\title{
Growth of the algae Isochrysis galbana and Tetraselmis suecica in water and sediment elutriate samples from the German Bight
}

\author{
J. Thain \\ Ministry of Agriculture, Fisheries and Food, Directorate of Fisheries Research, Remembrance Avenue, \\ Burnham-on-Crouch, Essex CM0 8HA, United Kingdom
}

\begin{abstract}
Surface water samples and sediments were sampled during the Bremerhaven Workshop at 9 locations on a transect from the inner German Bight to the Dogger Bank. Two species of algae were grown in the water samples and sediment elutriates prepared from the sediments. In both types of samples algal growth over $5 \mathrm{~d}$ was highest in the inshore samples and a graded response in growth was observed over the 5 inshore stations.
\end{abstract}

\section{INTRODUCTION}

During the workshop studies on bioassays for assessing biological water quality were carried out on the RV 'Valdivia' from the University of Hamburg, Germany. The algal growth bioassay described here was initiated at the workshop opportunistically using algal cultures grown for the maintenance and conditioning of oysters for the oyster embryo bioassay.

\section{METHOD}

Sampling was carried out at each of 9 stations along a transect from the inner German Bight to the Dogger Bank. The sampling positions had been carefully selected to cover a contaminant gradient (Stebbing et al. 1989). Water samples were collected using a Rosette sampler and sediment elutriates were prepared as described by Thain (1992). Two species of algae were tested: Isochrysis galbana and Tetraselmis suecica. The cell density of each culture was determined prior to the ship sailing. Cell counts were made using a haemacytometer slide and microscope. On board the ship the cultures were kept as cool as possible in ambient light until used for the bioassay. The bioassay was initiated on Day 4 of the cruise when all samples had been collected and processed. Sample volumes of $120 \mathrm{ml}$ in $250 \mathrm{ml}$ conical flasks were inoculated with each algal species to give a concentration of $5 \times 10^{4}$ cells $\mathrm{ml}^{-1}$ (based on the pre-cruise concentration) of sample. All flasks were incubated at ambient temperature (approximately $18^{\circ} \mathrm{C}$ ) on an orbital shaker at $100 \mathrm{rpm}$ in constant light. On Day 5 of the incubation period the vessel docked and the flasks were taken ashore and cell counts determined using a microscope. For the $T$. suecica cultures the incubation period was extended for a further $4 \mathrm{~d}$. At the start of the bioassay samples were also taken and preserved for nutrient analysis (Kirkwood 1989).

\section{RESULTS}

The growth of Isochrysis galbana in water samples and sediment elutriates for each station was similar (Fig. 1). Along the transect growth was highest at the inshore Stn 1 and decreased progressively to Stn 4 ; thereafter the cell densities measured were fairly constant.

The growth of Tetraselmis suecica over $5 \mathrm{~d}$ is shown in Fig. 2. Cell density was highest in sediment elutri- 


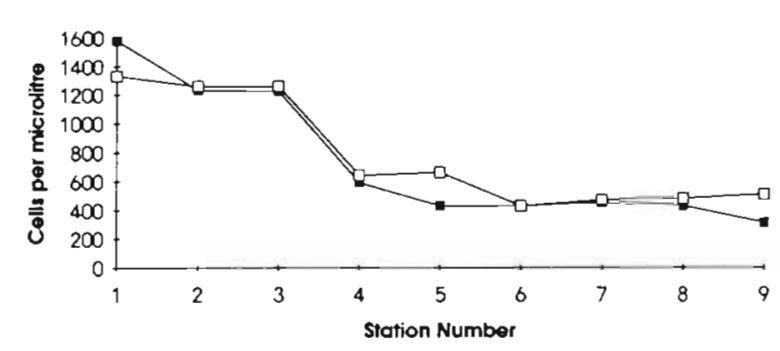

Fig. 1. Isochrysis galbana. Five day growth in water (-) and sediment elutriates $(\square)$

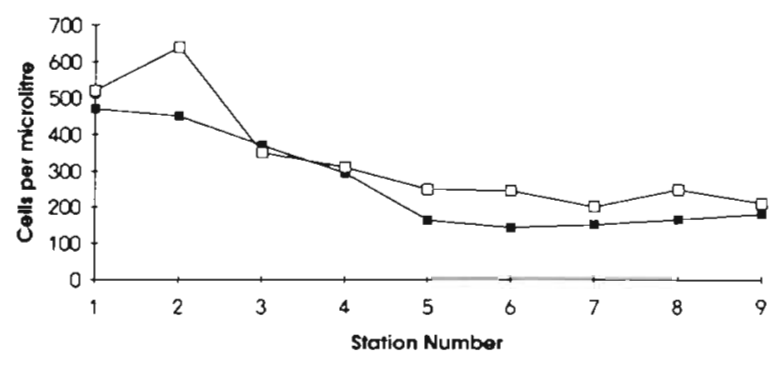

Fig. 2. Tetraselmis suecica. Five day growth in water $(\boldsymbol{\nabla})$ and sediment elutriates (0)

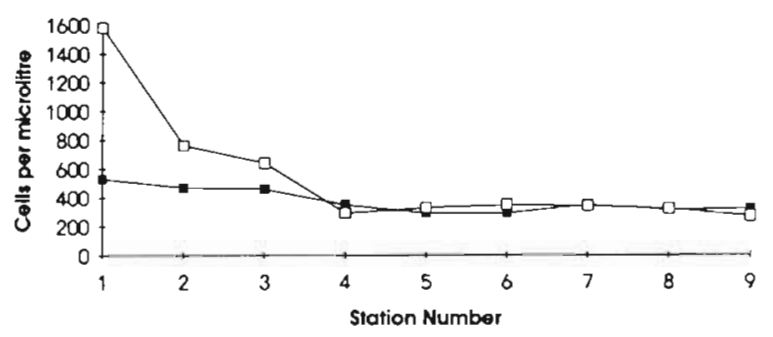

Fig. 3. Tetraselmis suecica. Nine day growth in water $(-)$ and sediment elutriates (a)

ates in 8 of the 9 stations. Algal growth in both the water and sediment elutriate samples decreased progressively from Stns 1 to 5 . In samples from Stns 5 to 9 the cell densities were similar.

Fig. 3 shows the growth of Tetraselmis suecica after $9 \mathrm{~d}$ incubation. In the water samples from Stns 1 to 3 cell densities were similar to the Day 5 values indicating a possible exhaustion of nutrients during the early incubation period. However, cell densities in samples from Stns 4 to 9 showed a 2 -fold increase on the Day 5 values. A similar 2 -fold increase in cell density was measured in the sediment elutriate samples from Stns 4 to 9 . In the sediment elutriates from Stns 1 to 3 algal growth continued to increase and was greatest at $\operatorname{Stn} 1$.

The concentration of phosphate, nitrate, nitrite and silicate was measured in all water and sediment elutriates (Fig. 4), with the exception of Stn 7 where the water sample was lost. In general nutrients were higher in the sediment elutriates than in the water column samples. There was no apparent trend in
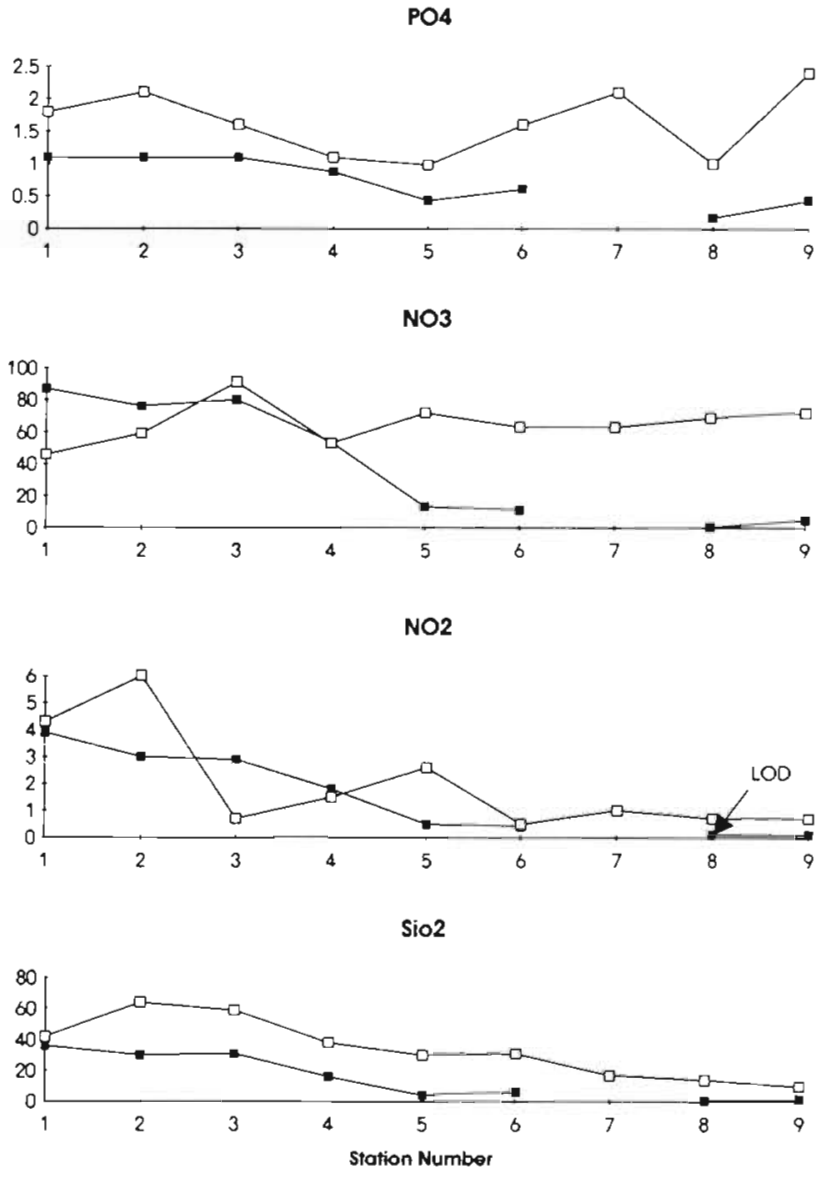

Fig. 4. Nutrients in water column (-) and sediment elutriates (a). All values $\left(y\right.$-axis) are $\mathrm{mmol} \mathrm{l}^{-1}$; LOD $=$ limit of detec tion $<0.1$

phosphate concentration along the transect. However, nitrate, nitrite and silicate concentrations in water and nitrite and silicate in sediment elutriates showed a general decrease from the inner 2 stations to Stn 5 .

\section{DISCUSSION AND CONCLUSION}

The 2 algal species grew well in all samples tested; cell density increased by at least 4 -fold and 3-fold of the inoculum concentration for Isochrysis galbana and Tetraselmis suecica respectively. However, it should be borne in mind that the starting concentrations were nominal and based on cell densities determined $4 \mathrm{~d}$ prior to performing the bioassay. The greatest increase in algal growth was measured in water and sediment elutriate samples from the 4 innermost stations of the transect. The nutrient analyses suggest that this may have resulted from the higher nitrogen levels measured at these same stations. The higher concentrations of silicate would not affect the cell growth of these 
algal species. During the $5 \mathrm{~d}$ exposure period there was little difference between water column and sediment elutriate samples. When the exposure period was extended to $9 \mathrm{~d}$ in the test with Tetraselmis suecica there was a clear difference between the 2 types of samples; cell concentrations were much greater in the sediment elutriate samples from Stns 1 to 3 . This suggests that there was a greater availability of nutrients in these sediment elutriates. This is not entirely borne out in the nutrient analyses, however, it is not only the quantity of N, P and Si that is important for algal growth but the relative proportions of these elements.

Other bioassays (including the oyster embryo bioassay) measured deleterious effects in sediment and surface micro-layer samples at some of the inshore stations. The results of these tests give no indication of toxicity to the phytoplanktonic species in any of the samples. The work was carried out under difficult and restrictive conditions at sea but has clearly demonstrated the usefulness of the bioassay in providing a biological measure of the nutrient status of the sea.

\section{LITERATURE CITED}

Kirkwood, D. S. (1989). Simultaneous determination of selected nutrients in sea water. C.M./ICES, C:29, 12 pp. (mimeo)

Stebbing, A. R. D., Dethlefsen, V., Heip, C., Thurberg, F. (1989). ICES/IOC Workshop on the biological effects of contaminants, Bremerhaven, Federal Republic of Germany, 12-30 March 1989. C.M./ICES, E:40, 14 pp. (mimeo)

Thain. J. E. (1992). Use of the oyster Crassostrea gigas embryo bioassay on water and sediment elutriate samples from the German Bight. Mar. Ecol. Prog. Ser. 91: 211-213 